\title{
Effect of cloudiness on solar global, solar diffuse and terrestrial downward radiation at Badajoz (Southwestern Spain)
}

\section{Efecto de la nubosidad en la radiación solar global y difusa y en la radiación terrestre descendente en Badajoz (Suroeste de España)}

\author{
G. Sánchez $\left.{ }^{*}\right)$, A. Serrano, M.L. Cancillo \\ Department of Physics, University of Extremadura, Avd. de Elvas s/n 06006 Badajoz,Spain. \\ (") Email: guadalupesh@unex.es \\ Recibido / Received: 30/01/2011. Aceptado / Accepted: 30/08/2011.
}

\begin{abstract}
:
Among all the components participating in the Earth radiation balance, clouds exhibit a large uncertainty in their characterization and quantification, partially due to their complex interaction with radiation. Although they play a key role attenuating and controlling the solar radiation and absorbing, scattering and emitting infrared radiation, their description is still very poor and more detailed studies are demanded. In order to contribute to that aim, simultaneous measurements of solar global irradiance, solar diffuse irradiance and downward infrared irradiance on a one-minute basis were performed at a radiometric station located in the Campus of the University of Extremadura in Badajoz (Spain). In this study the information provided by solar irradiance and its partitioning direct-to-diffuse, and by downward infrared irradiance is compared for some particularly interesting cases of study: cloud-free, partially cloudy and overcast. It is noted that infrared radiation does not exhibit the variability shown by the global solar radiation and directdiffuse partition in the different conditions analysed. The results emphasize the joint use of measurements of solar and infrared radiation which positively contribute to achieve a thorough description of the cloudiness field.
\end{abstract}

Keywords: Global Radiation, Diffuse Radiation, Infrared Radiation, Cloudiness.

\section{RESUMEN:}

Entre todos los componentes que participan en el balance radiativo terrestre, las nubes presentan una gran incertidumbre en su caracterización y cuantificación, en parte debido a su compleja interacción con la radiación. A pesar de que juegan un papel clave en la atenuación y el control de la radiación solar y en la absorción, dispersión y emisión de la radiación infrarroja, su descripción es todavía escasa por lo que son necesarios estudios más detallados. Con el fin de contribuir a una mejor descripción de las condiciones de nubosidad (de la cubierta nubosa), se han tomado medidas simultáneas de radiación solar global, radiación solar difusa y radiación infrarroja descendente en la estación radiométrica situada en el Campus de la Universidad de Extremadura en Badajoz (España). En este estudio, la información proporcionada por la radiación solar, su partición directa difusa y la radiación infrarroja se comparan en algunos casos particularmente interesantes: situaciones despejadas, parcialmente cubiertas (nubes rotas) y totalmente cubiertas. Se observa que la radiación infrarroja no presenta la variabilidad mostrada por la radiación solar global y su partición directadifusa en las diferentes condiciones estudiadas. Este hecho pone de manifiesto la necesidad del estudio simultáneo de las medidas de radiación solar global e infrarroja para lograr una descripción detallada del campo de nubosidad.

Palabras clave: Radiación Global, Radiación Difusa, Radiación Infrarroja, Nubosidad. 


\section{REFERENCIAS Y ENLACES / REFERENCES AND LINKS}

[1]. M. A. Atwater, J. T. Ball, "A surface solar radiation model for cloudy atmospheres”, Mon. Weather Rev. 109, 878-888 (1981).

[2]. G. W. Paltridge, "Infrared emissivity, shortwave albedo, and the microphysics of stratiform water clouds", J.Geophys. Res. 79, 4053-4058 (1974).

[3]. F. Kasten, G. Czeplak, "Solar and terrestrial radiation dependent on the amount and type of cloud". Sol. Energy 24, 177-189 (1980).

[4]. C. E. Duchon, M. S. O'Malley, "Estimating cloud type from pyranometer observations", J. Appl. Meteorol. 38, 132-141 (1999).

[5]. A. J. Drummond, "On the measurement of sky radiation", Arch. Meteorol. Geophys. Bioklim. Ser.B 7, 413-436 (1956).

[6]. R. Perez, P. Ineichen, R. Seals, A. Zelenka. "Making full use of the clearness index for parameterizing hourly insolation conditions", Sol. Energy 45, 111-114 (1990).

[7]. F. Kasten, "A new table and approximate formula for relative optical air mass", Arch. Meteorol. Geophys. Bioklimatol. Ser. B 14, 206-223 (1966).

[8]. http://www.soda-is.com/eng/index.html

[9]. B. Molineaux, T. Ineichen, J. J. Delaunay, "Direct luminous efficacy and atmospehric turbidityimproving model performance”, Sol. Energy 55, 125-137 (1995).

\section{Introduction}

It is well known that clouds are a strong modulator of the shortwave and longwave components of the earth's radiation budget. Clouds affect solar and terrestrial energy fluxes in different ways and sometimes produce opposite effects. The reflection of solar radiation and the greenhouse effect of terrestrial radiation depends on several cloud parameters: droplet size distribution, cloud density, thickness, altitude, temperature profile, etc. Although it is widely considered that the net effect of clouds is to cool the climate system, due to the high variability of cloud cover and the variety in their spatial distribution, there is still much uncertainty about the effect of clouds on the radiation. Thus, for instance, the inclusion of the clouds in climate models remains problematic and is subject to continuous changes. In recent years the sensitivity to the importance of clouds and radiation in studies of the earth's climate has been renewed. Also, it is widely recognized that an improved knowledge of the cloud properties and their variation in space and time is crucial for studies of global climate change.

The study of the cloudiness and its effect on radiation have been addressed applying different methodologies to a wide variety of measurements and data of different nature. Along with the classification of clouds by visual observation from meteorological stations at the earth's surface, the number of objective measurements performed by different instruments such as lidar, ceilometer and sky cameras from surface or satellite have notably increased in the last two decades. In addition to the description of cloudiness, the effect of clouds on the radiation balance at different wavelengths needs to be quantified.

Several research studies have been carried out in order to determine reliable relationships between short-wave and long-wave radiation fluxes measured at the ground and clouds parameters such as cloud amount and cloud type $[1,2]$. Such relationships have allowed the development of reliable methodologies for the retrieval of useful information about the cloud parameters from ground-based radiation measurements.

However, most of the studies related to cloudiness have focussed on the analysis of only short-wave radiation measurements $[3,4]$ and scarce research on the complete effect of clouds on the different wavelengths has been conducted. Thus, studies dealing with the simultaneous effect of cloudiness on the solar and on the terrestrial radiation are needed to improve the understanding of the absorption, scattering and emission processes suffered by solar and terrestrial radiation in presence of clouds. 
In this framework, this paper is aim at the analysis of the effect of cloudiness in the solar and terrestrial radiation reaching the ground. It will analyse the behaviour of direct, diffuse and global solar radiation as well as terrestrial infrared radiation under different typical sky conditions such as cloud-free, partially cloudy and overcast.

\section{Data}

Solar global and diffuse irradiance and infrared irradiance were measured at the radiometric station located on the terrace of the building of Physics Department at the University of Extremadura in Badajoz (Spain). The coordinates of the station are $38^{\circ} 52^{\prime} 58^{\prime \prime} N, 7^{\circ} 0^{\prime}$ 38" $W$ and $199 \mathrm{~m}$ a.s.l. Measurements were recorded at one-minute basis for a period of study extending from 23 November 2009 to 27 October 2010.

Solar global irradiance with wavelengths between 310 and $2800 \mathrm{~nm}$ was measured with a pyranometer CMP11. This instrument allows the measurement of global irradiance incident on a horizontal surface in an azimuth angle of $360^{\circ}$. Diffuse irradiance was measured by a second CMP11 pyranometer installed on a CM121 shadow ring that prevents direct radiation reaching the pyranometer sensor. In order to guarantee the quality of diffuse radiation data, the shadow ring has been daily adjusted to ensure the continuous and complete shading of the piranometer dome. Additionally, measurements have to be corrected for the obstruction by the ring of a certain portion of diffuse radiation. For this purpose, the method proposed by Drummond [5] and also recommended by the manufacturer of the shadow ring has been used. These have been the first measurements of solar diffuse radiation taken at this station. For measuring the terrestrial infrared radiation a CG1 pirgeometer has been used. This instrument measures downward infrared radiation with wavelengths between 4 and $40 \mu \mathrm{m}$. All these instruments are manufactured by Kipp \& Zonen. Simultaneous data from all sensors were collected every ten seconds by a CR1000 datalogger (Campbell Scientific) and recorded as one-minute average.
A very important aspect to guarantee the data quality is the calibration of the instruments. The instruments used in this study have been calibrated in September 2009 by intercomparison with a reference pyranometer (CM11, \#027771) at the Atmospheric Sounding Station (ESAt, INTA) located in El Arenosillo, Huelva, Spain $\left(37.1^{\circ} N, 07.06^{\circ} W\right)$. The instrument used as reference had been previously calibrated at the World Radiation Center (WRC) in Davos, Switzerland. The calibration factor was obtained as the average of the ratios between the voltage signal of each radiometer and the irradiance measured by the reference pyranometer.

In this paper, one-minute measurements of global and diffuse solar radiation and infrared radiation have been used. After a careful review of data, to detect and analyse possible anomalous values, only a $1.1 \%$ of data were discarded.

\section{Methods}

The study has been divided into two sections. Firstly the behaviour of direct, diffuse and global irradiance, as well as infrared radiation on different typical days selected by visual inspection has been analysed. These typical days correspond to different cloudiness conditions: cloud-free, partially cloudy and overcast. Secondly, cases corresponding for clear, partially covered and overcast situations have been selected. The index proposed by Perez et al. [6] has been used for that aim. It is defined as follows:

$$
k^{\prime}=\frac{k_{t}}{1.031 \cdot \exp \left(\frac{-T_{L}}{0.9+9.4 / m}\right)+0.1},
$$

where $T_{L}$ is the Linke's turbidity parameter, $m$ is the relative air mass given by Kasten [6] and $k_{t}$ is the clearness index, defined as the ratio between horizontal irradiance reaching the earth's surface and the horizontal irradiance arriving at the top of the atmosphere. This index measures the attenuation that the radiation suffers when it passes through the atmosphere. According to the SODA database [7], the average monthly value of 2.7 was considered for the Linke turbidity parameter. 
Following Molineaux et al. [8], cloud-free conditions are identified as those with Perez's index $k_{t}^{\prime}$ value greater than 0.7. On the other hand, cases are classified as overcast when kt' is lower than 0.4. This threshold has been chosen by visual inspection of several overcast situations. Other cases corresponding to intermediate values of $k_{t}^{\prime}$ were associated to partially cloudy conditions. Once different situations have been classified into the three mentioned categories, the behaviour of the clearness index kt, the ratio of diffuse to global, $\mathrm{kd}$, and the infrared radiation corresponding to different cloudy conditions have been analysed. The parameter $k_{t}$ is defined as the ratio between diffuse and global irradiances on a horizontal plane at the earth's surface.

\section{Results}

Figure 1 shows the direct irradiance, diffuse, global and downward IR for three typical days which have been selected by visual inspection. During a cloud-free day (Figure 1a) the global, direct and diffuse irradiance show a high symmetry around noon. In this case, the attenuation of radiation is mainly due to its outward dispersion and a low absorption by atmospheric constituents. For high solar zenith angles the diffuse component increases its relative weight due to a larger optical path crossed by the radiation in these situations. On the other hand, the downward IR radiation linearly increases throughout the day with a slight decline at the last hours of the day. This behaviour is due to the progressive increase in the atmosphere temperature throughout the day and its cooling at the final hours of the day.

Under uniform cloud conditions (Figs. 1(a) and $1(\mathrm{c}))$ the short-wavelength radiation is remarkably reduced being the diffuse component the most important component. In these situations the downward IR radiation reaches higher values than in cloud-free conditions due to the downward emission of IR radiation by clouds.

Under partially cloudy conditions (Fig. 1(b)) all radiation flows show a high variability due to the random presence of different types of clouds
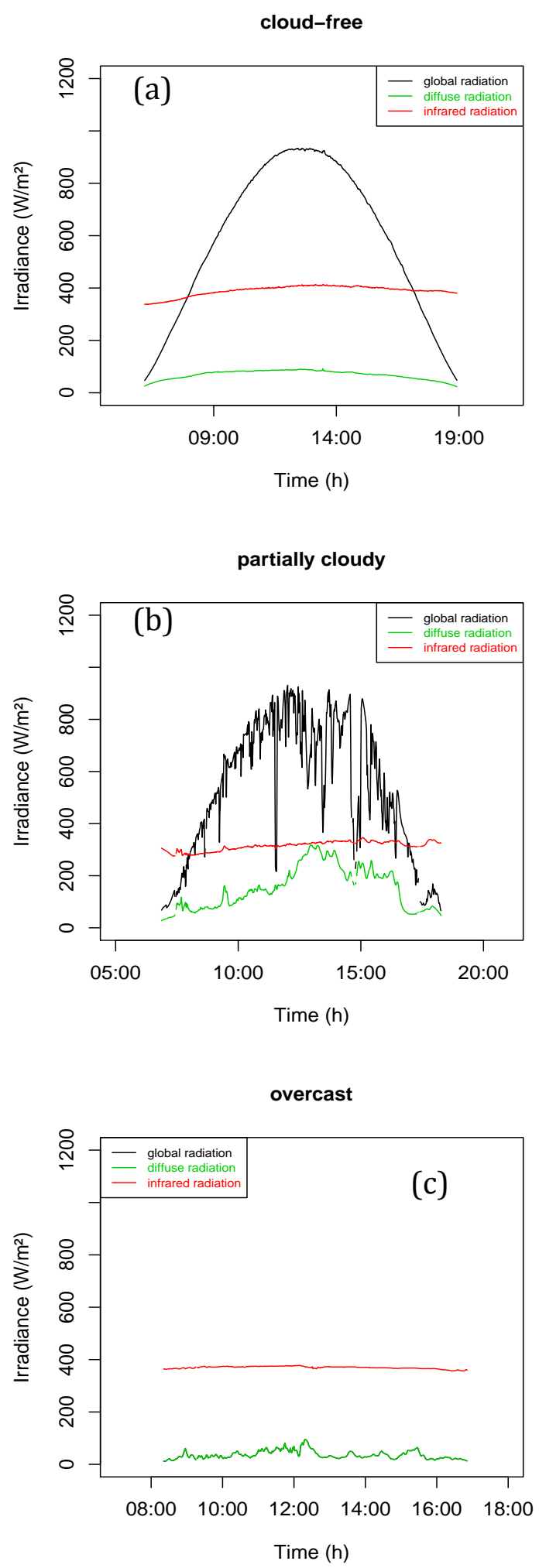

Fig. 1. Solar global, diffuse and infrared irradiance at three typical days corresponding to (a) cloud-free, (b) partially cloudy and (c) overcast conditions. 
and their complex spatial distribution. The variation observed for IR radiation is less pronounced than for short-wavelength radiation due to insensibility to whether the sun is shaded by clouds or not. In the case of short wavelength radiation, the prevalence of direct or diffuse components highly depends on the characteristics and spatial distribution of cloudiness. Sometimes, the existence of broken clouds enables focalisation and multiple reflection phenomena causing an increase in global and diffuse radiation to values even higher than those reached under cloud-free conditions. The attenuation or increase of radiative fluxes by clouds will highly depend on the cloud layer extension, its relative-to-the-sun position, and some clouds properties such as temperature and optical thickness.

The classification of the cases according to the index proposed by Perez et al. [6] results in $75 \%$ cloud-free, $7 \%$ partially cloudy and $18 \%$ overcast.

Table I

Mean and standard deviation of the clearness index $k_{t}$, the proportion of diffuse $k_{d}$, and the infrared irradiance for the three sky conditions: cloud-free, partially cloudy and overcast.

\begin{tabular}{|c|c|c|c|}
\hline & $\begin{array}{c}\text { Cloud- } \\
\text { free }\end{array}$ & $\begin{array}{c}\text { Partially } \\
\text { cloudy }\end{array}$ & Overcast \\
\hline mean $\left(k_{t}\right)$ & 0.7 & 0.42 & 0.22 \\
\hline sd $\left(k_{t}\right)$ & 0.11 & 0.10 & 0.09 \\
\hline mean $\left(k_{d}\right)$ & 0.22 & 0.66 & 0.79 \\
\hline sd $\left(k_{d}\right)$ & 0.16 & 0.18 & 0.08 \\
\hline $\begin{array}{c}\text { mean (IR) } \\
\left(\mathrm{W} / \mathrm{m}^{2}\right)\end{array}$ & 354.9 & 364.3 & 376.7 \\
\hline $\begin{array}{c}\mathbf{s d}(\mathbf{I R}) \\
\left(\mathrm{W} / \mathrm{m}^{2}\right)\end{array}$ & 46.8 & 37 & 27.3 \\
\hline
\end{tabular}

Under cloud-free conditions a mean $k_{t}$ of 0.7 is found with $90 \%$ of the values between 0.5 and 0.85 (Fig. 2(a)). Those extreme cases with clearness index values below 0.5 correspond to high solar zenith angle conditions where the attenuation within the atmosphere increases due to a larger optical path crossed by the radiation. In these cases $k_{d}$ remains low with a mean value of 0.22 (Fig. 2(b)) and $85 \%$ of values lower than 0.4 .

The cases of partially cloudy conditions are characterised by a mean $k_{t}$ value of 0.42 , significantly lower than in cloud-free cases. This fact indicates that, although broken clouds can potentially increase the radiation reaching the ground due to focalisation phenomena, its overall effect is the additional attenuation of $40 \%$ radiation with respect to the values
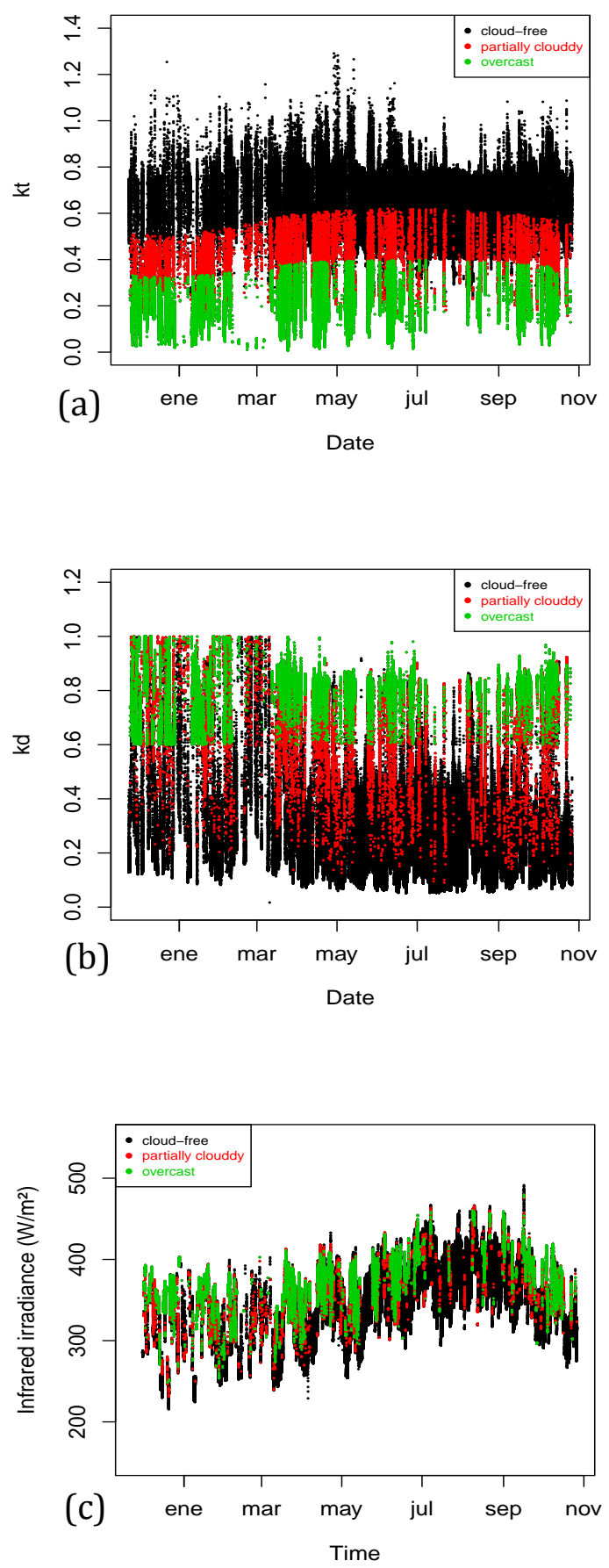

Fig. 2. Temporal evolution of clearness index $k_{t}$, ratio of diffuse $k_{d}$, and infrared radiation for the period of study. 
measured under cloud-free conditions. The proportion of diffuse radiation increases to a mean value of 0.66 , three times higher than under cloud-free conditions.

On the other hand, overcast conditions are clearly associated to high values of $k_{d}$, being higher than 0.6 with a mean value of 0.79 . Additionally, the $k_{t}$ values reaches the lowest values, with a mean value around 0.2 . In compared with values obtained under cloud-free conditions, this reduction means an attenuation by clouds of $50 \%$ of the incoming radiation. Regarding the infrared radiation (Fig. 2(c)), it shows a seasonal pattern substantially driven by the air temperature and a range of variation of approximately $100 \mathrm{~W} / \mathrm{m}^{2}$ around it.

\section{Conclusions}

Radiative fluxes that reach the earth's surface highly depend on the particular cloud conditions existing at a certain time. Not only the amount and type of clouds but also their spatial distribution and physical properties substantially affect their effects on the radiation.

The results have provided some quantification of the influence of the cloudiness on the solar and terrestrial radiation that reaches the earth's surface. The discussion of the values reached by the clearness index, the proportion of diffuse and the infrared irradiance under different conditions suggests the need to consider different aspects and wavelength intervals of the radiation in order to have a thorough description of the cloudiness effects. According to the results, the need to routinely measuring both solar and infrared radiation along with the direct and diffuse components is emphasized.

\section{Acknowledgements}

This work was supported by the research project CGL2008-05939-C03-02/CLI granted by the Ministerio of Ciencia e Innovación de España. 